\title{
Heteranthia decipiens Nees \& Martius (Solanaceae), uma espécie rara, exclusiva da flora brasileira
}

\author{
Lúcia d'Avila Freire de Carvalho'
}

\begin{abstract}
The author shows a monotipic genus, exclusively brazilian and little known - Heteranthia, with a morphological revision based on the current bibliography and examined colections. Results indicated new localities for the taxon which is typified here besides the descriptions of some vegetation and floral anatomical characteristics.
\end{abstract}

Keywords: Heteranthia, Solanaceae, Brasil.

\section{RESUMO}

A autora divulga um gênero monotípico, exclusivamente brasileiro e pouco conhecido Heteranthia Nees \& Martius, com uma revisão morfológica baseada na bibliografia existente e nas coleções examinadas, indicando novas localidades para o táxon, além de proceder a tipificação e descrever algumas características anatômicas, vegetativas e florais.

Palavras chave: Heteranthia, Solanaceae, Brasil.

\section{INTRODUÇÃO}

O gênero Heteranthia Nees \& Martius, monoespecífico, representado por $H$. decipiens, antes conhecido como Vrolikia polygaloides Spreng. e indicado para a família Primulaceae (Sprengel 1826), e sem dúvida uma espécie pouco conhecida com escassas coletas representadas nos herbários brasileiros e do exterior. Desde que foi descrita, nos meados do século passado por Nees \& Martius (1823), tem sido citada em poucos artigos relativos à morfologia e taxonomia (Hunziker 1979a, b) da família em questão e, consequentemente, não deve figurar identificada na maioria dos herbários. Por estas razões, parece interessante dar a conhecer sua distribuição geográfica e descrição morfológica mais detalhada com alguns comentários necessários à elucidação e discussão da posição taxonômica deste táxon entre as Solanáceas.

\section{POSIÇÃO TAXONÔMICA DE Heteranthia:}

Até o século passado após o trabalho de Sprengel (1826), esse gênero vinha sendo descrito para a família Scrophulariaceae, variando sua posição, apenas em nível de tribo, em função do sistema adotado ou critério do autor do artigo: na tribo Gratioleae (Endlicher 1836-40), na tribo Salpiglossideae (Bentham 1846), na tribo Leucophylleae (Bentham \& Hooker 1876) ou ainda na tribo Verbasceae (Wettstein 1895) entre os gêneros Eremogeton Standl. \& L.D.Williams, Ghiesbreghtia A.Gray e Leucophyllum Humb. \& Bompl., e mais recentemente, nessa mesma tribo por Barroso (1964). Com os estudos anatômicos de Solereder (1915), ficou definido a posição taxonômica de Heteranthia entre as Solanáceas, principalmente pelo arranjo bicolateral dos feixes vasculares no caule e nas folhas; situando-se entre os gêneros da tribo Salpiglossideae, pela presença dos quatro estames didínamos e pela forma da corola.

${ }^{1}$ Pesquisadora do Jardim Botânico do Rio de Janeiro e do Conselho Nacional de Desenvolvimento Científico e Tecnológico - CNPq 
Também por afinidades morfológicas é colocado próximo aos gêneros Browallia Linn. e Schwenckia Rooy ex Linneu.

Para D'Arcy $(1975,1979)$ Heteranthia situa-se melhor na subfamília Nolanoideae, principalmente pela presença do embrião reto, imerso no endosperma, e sementes de forma poliédrica, embora seja considerado "incertae sedis" para Hunziker (1979a).

\section{ANÁLISE TAXONÔMICA DA ESPÉCIE:}

Heteranthia decipiens Nees \& Mart., Nov. Act. Physico-medica (Nat. Cur.) 11(1): 41, t.3. 1823; Endl., Gen. Plant. no 3955: 684. 1836-40; Benth. in DC., Prodr. 10: 201. 1846; Wawra, Bot. Ergeb. Reis. 1: 82, t. 64. 1866; Benth. \& Hook., Gen. Plant. 2(2): 913. 1876; Wettst., Nat. Pflanz. Fam. 4(36): 107. 1895; Solereder, Bot. Zeit. 22(2): 113. 1898; Barroso, Rodriguésia 27: 19. 1964.

Vrolikia polygaloides Spreng., Syst. Veg. 3:157.1826. TIPO: "in via Felisbertia Decembri 1816". NEÓTIPO: Brasil, Estado da Bahia, município de Belmonte, Belém et al. 3263 (1.II.1967) (fl), CEPEC, K, RB, UB.

Figuras: 1-16.

Erva a subarbusto, ca. $40 \mathrm{~cm}$ alt., ereta, às vezes decumbente. Raízes adventíceas cilíndricas, até $2 \mathrm{~cm}$ compr., esparsas nos ramos e junto ao nó foliar. Ramos herbáceos a sublenhosos, cilíndricos, estriados, dicotômicos, pubescentes, tricomas simples, eretos e curvos. Folhas alternas, aos pares, desiguais em tamanho e na forma; pecíolo cilíndrico, até $0,6 \mathrm{~cm}$ compr.; lâmina membranácea, ovada a ovadolanceolada, $(2,5)$ 4,5-6cm compr., $(1,5)$ $2-4 \mathrm{~cm}$ larg., tricomas simples, esparsos no limbo e pubescente ao longo das nervuras, ou em ambas as faces, ápice obtuso ou arredondado, base levemente decorrente, atenuada, aguda ou truncada, margem inteira, por vezes sinuosa. Nervação camptódroma, nervuras secundárias ascendentes, alternas ou opostas, rede de nervuras laxa, poucas, terminações vasculares livres, simples, bífidas e múltiplas, às vezes com esclereídes; epiderme superior e inferior constituída por células de contorno ondulado, cutícula lisa em ambas as faces; estômatos limitados a epiderme abaxial, numerosos, anisocíticos, diacíticos e anomocíticos. Inflorescência axilar, subopositifolia ou terminal, racemosa, pauciflora, 12-15 flores; ramos dicotômicos, 4$10 \mathrm{~cm}$ compr. Flores alvacentas ou roxas, ca. $0,5 \mathrm{~cm}$ compr.; pedicelo cilíndrico, ca. $0,1 \mathrm{~cm}$ compr.; bractéolas linear-lanceoladas, 0,1$0,2 \mathrm{~cm}$ compr., pubescentes, tricomas simples. Cálice verde, campanulado, 0,3-0,4cm compr., membranáceo, 15-nervado, sendo 5 nervuras medianas às lacínias, as demais laterais, anastomosadas do ápice e até o terço médio do cálice; epiderme constituída por células de contorno ondulado, cutícula estriada na região dos estômatos; face interna glabra, face externa glabrescente, tricomas simples e glandulares; preforação valvar, lacínias agudas, até $1 \mathrm{~cm}$ compr., margem inteira, papilosa; persistente no fruto. Corola infundibuliforme, fauce ampliada, bilaciniada, lacínia menor indivisa, oblonga; lacínia maior curto-trilobada ou levemente emarginada, 4-nervuras anastomodadas na região apical; células epidérmicas em ambas as faces, de contorno ondulado, diferindo no tamanho, cutícula, às vezes, estriada; prefloração imbricada, lacínias plicadas, lacínia menor coberta pela maior. Androceu incluso, 4-didínamos, inseridos no tubo corolíneo em oposição a lacínia oblonga; filete filiforme, uninervado; antera bilocular, rimosa, deiscência longitudinal, extrorsa, tecas iguais nos estames superiores, desiguais nos inferiores, medifixas; conectivo globoso, vascularizado por uma nervura ramificada e anastomosada no ápice. Pólen subprolato, tricolporado, ós lalongado, superfície psilada, diâmetro polar 33,8-37,5 m e diâmetro equatorial 26,4-32,2 m. Gineceu glabro, estilete filiforme, curvado no ápice, até $0,7 \mathrm{~cm}$ compr., exserto, região estigmática apical reduzida, emarginada. Cápsula subglobosa, apiculada, septicida, bivalvar; valva membranácea a cartácea, lisa, nervada; epiderme constituída por células de contorno poliédrico na face 


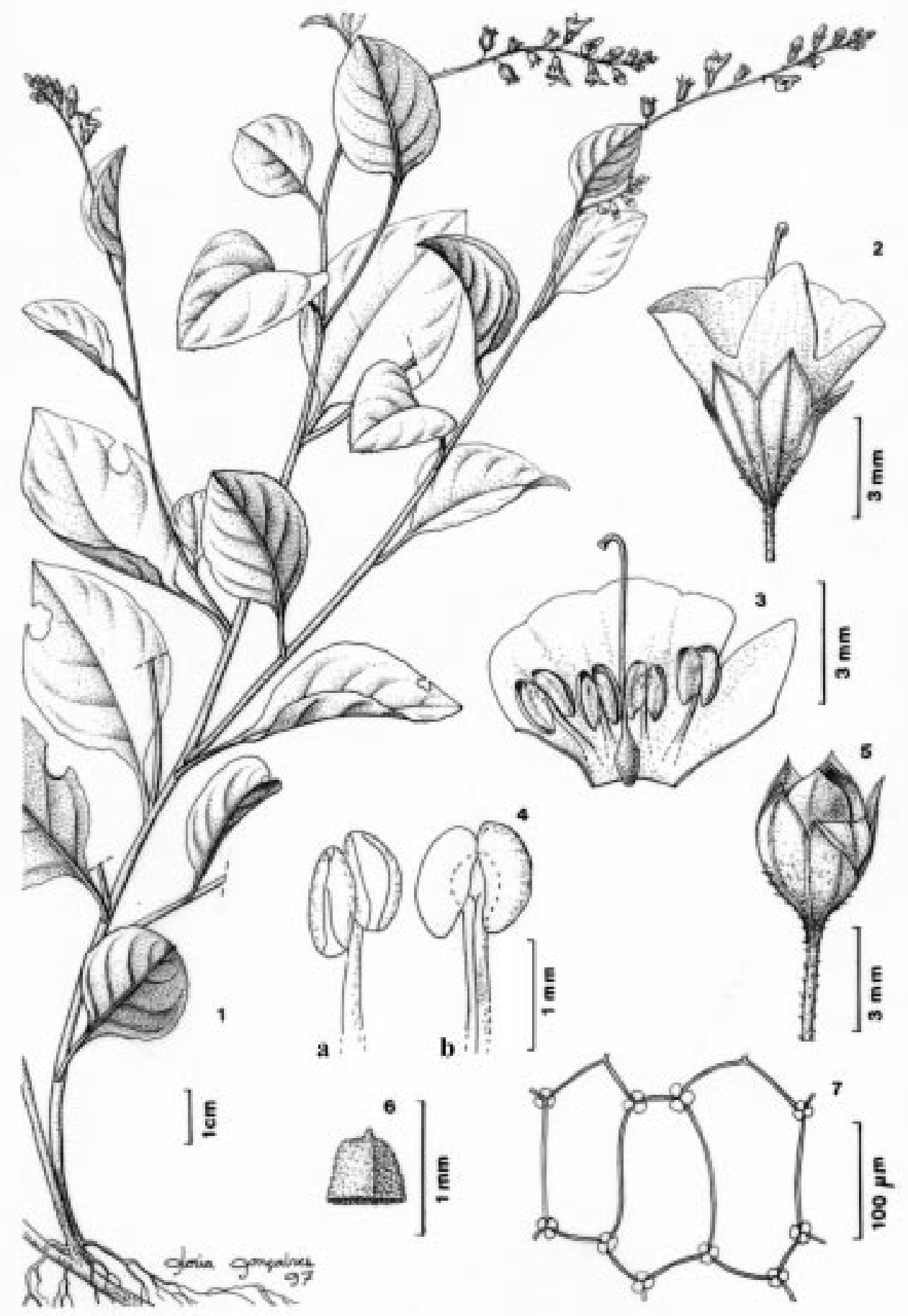

Heteranthia decipiens Nees \& Mart. (Belém et al. 3263, UB). Fig. 1 - ramo florífero e frutífero; fig. 2 - forma e relação cálice/corola; fig. 3 - corola/androceu e gineceu; fig. 4 - anteras: a - face ventral, b - face dorsal evidenciando o conectivo globoso; fig. 5 - cápsula bivalvar envolvida pelo cálice ampliado; fig. 6 - semente poliédrica; fig. 7 - segmento da testa da semente reticulado, com 3-grânulos nos ângulos das malhas. 

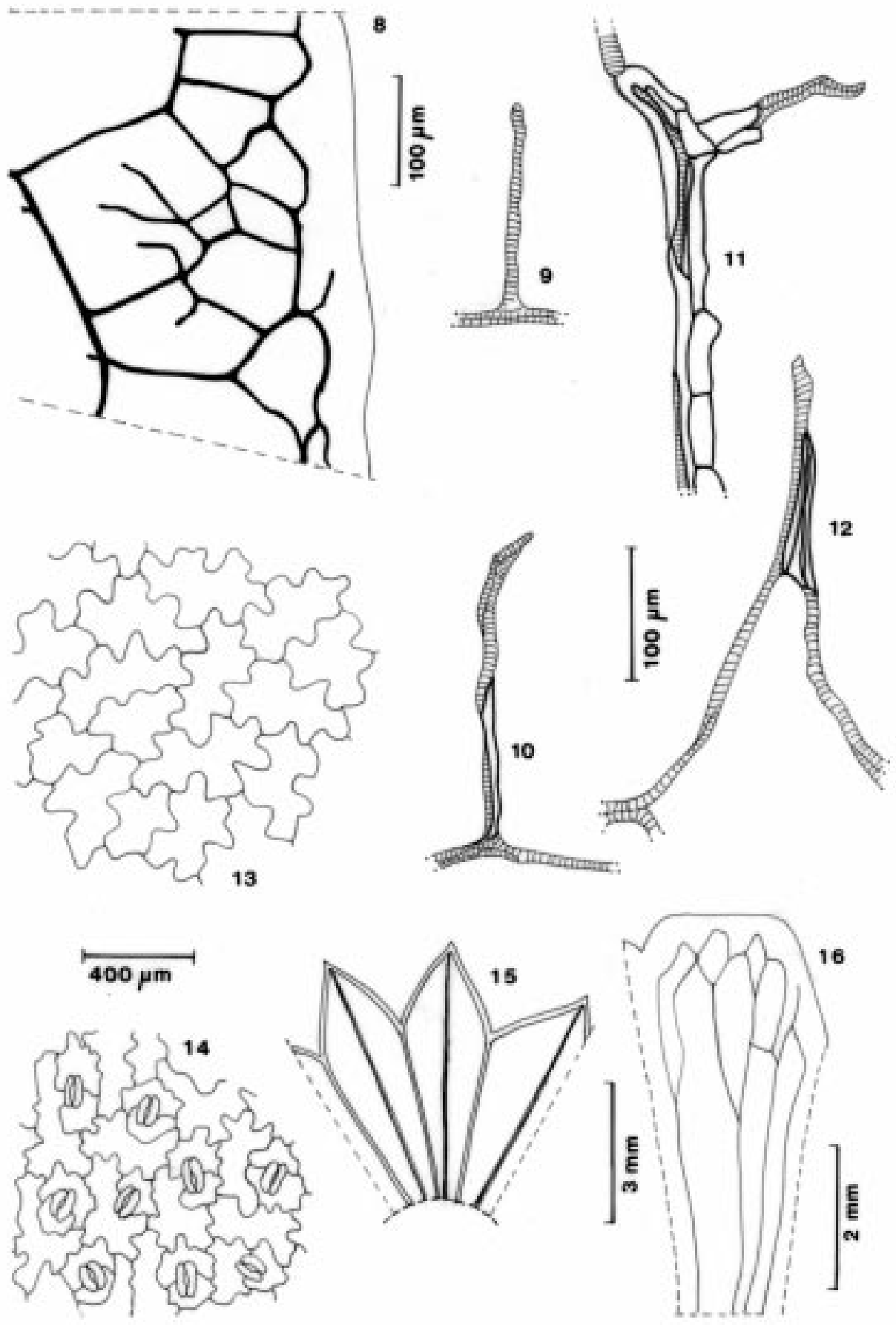

Heteranthia decipiens Nees et Mart. (Belémet al. 3263, UB). Nervação foliar: Fig. 8 - no bordo; figs. 9-12 - terminações vasculares da lâmina foliar; figs. 13-14 - epidermes ventral e dorsal com estômatos; Nervação: fig. 15 - segmentos do cálice; fig.16- segmento da corola. 
interna, parede delgada, cutícula estriada, epiderme da face externa constituída por células de contorno ondulado-estrelado e de paredes espessas. Semente acastanhada, poliédrica, testa reticulada, com três grânulos nos ângulos da malha; embrião reto, endosperma presente.

\section{COLEÇÕES EXAMINADAS:}

BRASIL: (1827) Martius s.n. BM, K; (1840) Riedel 129, GH, K, L; Sellow, K ex M; Sprengel s.n., MPU. BAHIA: (1865) Blanchet 795, BM, G, 1127. P; Blanchet 3553 e 3985 BR, K, P; mun. Jacobina, Jacobina, (1842) Blanchet 3559 BM, G, P; mun. Porto Seguro, BR 5, Km 21, (6.IX.1961) Duarte 6145 RB. MINAS GERAIS: mun. Congonhas, Congonhas do Campo, (30.VI.1884) Glaziou 15452 R; entre Carandaí e Ouro Preto, Glaziou 13823, BR, P. RIO DE JANEIRO: (IV.1883) Glaziou 19829 K; (V.1885) Glaziou s.n. K.

\section{ANÁlISE DAS COLEÇÕES E TIPIFICAÇÃO DO TÁXON:}

A localidade indicada por Nees \& Martius (1823) na obra princeps cita: "in via Felisbertia Decembri 1816" como o material botânico utilizado para descrever a nova planta, pode ser a mesma que se interpretou através da pesquisa bibliográfica, pela concordância parcial com o nome da localidade do município mineiro - Felisberto Caldeira, embora não se conheça o coletor. Este exemplar ainda não foi encontrado nos diversos herbários consultados.

Entre as coleções citadas por Wawra (1866), estão as de Blanchet (795, 3553,3559 e 3985) que foram coletadas no Estado da Bahia, em torno de 1865 , sem mencionar a localidade; o mesmo aconteceu com a coleção de Sellow, indicando apenas "in Brasilia", examinada por Bentham (1846) e Solereder (1915) para os estudos anatômicos, estão representadas em vários herbários europeus (B!,BR!,E!,G!,K!,L!,P! e TUB!).
Morfologicamente, as plantas de Sellow estão bem caracterizadas, correspondendo aos comentários da diagnose de Nees \& Martius (1823), às descrições ampliadas pelos autores subsequentes indicados na referência bibliográfica do táxon e aos estudos anatômicos de Solereder (1915), que determinaram a posição taxonômica do gênero.

Entre as plantas de Martius coletadas em 1827 , embora sejam as mais antigas entre as coleções históricas examinadas, poucos foram os exemplares localizados até o momento; somente em dois herbários: $\mathrm{BM}$ e $\mathrm{K}$, dentre os onze herbários investigados (BM, BR, E, G, GH, K, L, MPU, R, RB e UB). Os mesmos resultados foram observados em relação à coleção de Riedel 129, depositada somente nos Herbários de GH, K e L.

Considerando a representatividade de coletas recentes deste século, nos herbários brasileiros, a excelência das amostras para documentar a morfologia do táxon e ainda a exclusividade de ocorrência no país, estabeleceu-se o Neótipo com base nas amostras de Belém et al. 3263 (01.02.1967) depositadas nos herbários CEPEC, K, RB e UB.

\section{DISTRIBUIÇÃO GEOGRÁFICA E FLORAÇÃO:}

Esta espécie, exclusiva da flora brasileira, primeiramente descrita para o Estado de Minas Gerais, tem sua área de ocorrência ampliada para outras localidades deste Estado e ainda para os Estados do Rio de Janeiro e Bahia, com base nas coletas documentadas neste artigo, algumas do século passado, mas ainda não divulgadas à comunidade científica.

Conhecida para Ilhéus e Itaparica (Wawra 1866), neste século foi coletada nas localidades de Belmonte e Porto Seguro, situadas no Estado da Bahia, junto à região de cultivo de cacau e em região de mata recentemente derrubada, segundo as informações da etiqueta de coleta do botânico A.P. Duarte $\left(\mathrm{n}^{\circ} 6145, \mathrm{RB}\right)$. 
O número insuficiente de amostras e de informações "in shedulae" não permite estabelecer o período de floração e de frutificação, apenas de se indicar os meses de abril à junho para floração e os meses de fevereiro e setembro para frutificação, segundo as coleções recentes; é considerada pela literatura como uma planta perene.

As folhas persistem durante a floração e a frutificação, o mesmo acontecendo com o cálice durante a frutificação, fenômeno de interesse para as coletas vegetativas, alertando os botânicos na busca da espécie.

\section{CATEGORIA CONSERVACIONISTA:}

Vulnerável (VU), significando, segundo os critérios da IUCN (1994), que a planta corre risco de extinção a médio prazo. Através das informações fornecidas pelos botânicos coletores nas etiquetas das exsicatas, são plantas que embora constituam populações na natureza, ocupam áreas de risco, como zona de cultivo ou região de mata com forte ação antrópica.

Acrescenta-se, ainda, a falta de representação nos herbários brasileiros, conforme constatou-se durante visitas realizadas a diferentes instituições, principalmente das regiões Sudeste e Sul.

\section{CONSIDERAÇÕES FINAIS:}

Heteranthia decipiens é aceita no presente estudo como pertencente a família Solanácea, pelas características morfológicas evidenciadas, principalmente pelo arranjo bicolateral dos feixes vasculares do caule e folhas.

É considerada, também, uma planta rara e vulnerável da flora brasileira, pelo aspecto herbáceo-arbustivo, necessitando ser indicada para a Lista Oficial de plantas ameaçadas de extinção.

\section{AGRADECIMENTOS:}

À Dra. Graziela M. Barroso, pesquisadora do Jardim Botânico do Rio de Janeiro, que encontrou em nosso herbário um exemplar, identificou-o e sugeriu o estudo para divulgação. Ao Conselho Nacional de Desenvolvimento Científico e Tecnológico pela bolsa concedida à autora. Aos curadores dos herbários nacionais e estrangeiros, pelo empréstimo de material botânico, imprescindível para a realização deste estudo.

\section{REFERÊNCIAS BIBLIOGRÁFICAS}

Barroso, G. M. 1964. Scrophulariaceae indígenas e exóticas no Brasil. Rodriguésia 27: 9-64, 51 figs., 39 fotos.

Bentham, G. 1846. Scrophulariaceae. In De Candolle, A. (ed.). Prodromus 10: 186201. Paris.

Bentham, G. \& Hooker, J. D. 1876. Scrophulariaceae. In Benth. \& Hook. (eds.). Gen. Plant. 2(2): 913-926. Lovell Reeve \& Co. London.

D'Arcy, W. G. 1975. The Solanaceae: an overview. Solanaceae Newsletter, Missouri Bot. Gard. 2: 8-15. 1979. The Classification of the Solanaceae. In Hawkes, J. G., Lester, R. N. \& Skelding, A. D. (eds.). The Biology, Taxonomy and Chemistry of the Solanaceae. Academic Press. London, p. 3-47.

Endlicher, S. L. 1836-40. Scrophulariaceae. Gen. Plant. 9: 684. Wien (Fr. Beck).

Hunziker, A. T. 1979a. South American Solanaceae: A synoptic survey. In J.G. Hawkes, R. N. Lester and A. D. Skelding (eds.). The Biology, Taxonomy and Chemistry of the Solanaceae. Academic Press London, p. 49-85. 1979b. The Solanaceae in the Neotropics: A critical appraisal. In K. Larsen \& B. Hoem - Nielsen (eds.). Tropical Botanical. Academic Press London, 2 p. 355 -364, 4 figs. 
IUCN Red List Categories. 1994. IUCN Special Survival Comission. 40th Meeting of the IUCN Council. Gland, Switzerland, 21pp.

Nees von Esenbeck, C. G. D. \& Martius, K. F. P. von. 1823. Primulaceae in Beitraz zur Flora Brasiliens von Maximilian.Nov. Act. Phys. - Med. (Acad. Caeser. Leopol. Carol.) Nat. Curios. 1: 41-43, t. 3.

Solereder, H. 1915. Uber die Versetzung der Gattung Heteranthia von den Scrophulariaceen zu den Solanaceen. Beih. Bot. Centralbl. Bd. 33 (2) helft. 1: 113-117.

Sprengel, K. P. J. 1826. Vrolikia polygaloides Sprengel. In Linn. Syst. Veg. 2: 165.

Wawra, H. R. Von Fernsee. 1866. Heteranthia. In Botanische Ergebnisse der Reise, Pr. Maximilian I nach Brasilien, Wien. 1: 82, t. 64.

Wettstein, R. von. 1895. Scrophulariaceae. In Engler, H. G. A. and Prantl, K. A. E. Die Naturliche Pflanzenfamilien, Engelmann, Leipzig. 4: 4-38. 
